NBER WORKING PAPERS SERTES

ESTIMATING EXPECTED EXCHANGE RATES UNDER TARGET ZONES

Zhaohui Chen

Alberto Giovannini

Working Paper No. 3955

\author{
NATIONAL BUREAU OF ECONOMIC RESEARCH \\ 1050 Massachusetts Averue \\ Cambridge, MA 02138 \\ January 1992
}

We are grateiul to Lars Svensson for discussions and for having provided the dataset originally compiled by Andrew Rose. We thank Bob Cumby for helpful conversations. We also thank Bob Blake for providing a dataset and Ching Wang for supplying a Fortran subroutine. This paper is part of NBER's research program in International Studies. Any opinions expressed are those of the authors and not those of the National Bureau of Economic Research. 
NBER Working Paper \#3955

January 1992

\title{
ESTIMATING EXPECTED EXCHANGE RATES UNDER TARGET ZONES
}

\begin{abstract}
This paper develops a simple econometric procedure for estimating expected exchange rate under target zones. We employ the linear projection methodology to make predictions without relyisg on any prior structural or distributional assumptions, and at the sarne time demonstrate that stich a methodology has to be modified in an important way to account for the presence of the fluctuation band. Our empirical results show that the band effect is nontrivial for narrow target zones such as the Bretton Woods system. We also develop a method to estimate the shapes of the unconditional distributions of exchange rates under target zones. The empirical results show that the unconditional distributions of exchange rates can take several different shapes, which may comespond to possibly widely different monetary and exchange-rate intervention policies. We also show how to use the projection equations and the information about the band to test the credibility of the exchange rate regimes.
\end{abstract}

Zhaohui Chen

Graduate School of Business

622 Uris Hall

Columbia University

New York, NY 10027

\author{
A.lberto Giovannini \\ Graduate School of Business \\ 622 Uris Hal] \\ Columbia University \\ New York, NY 10027 \\ and NBER
}




\section{Introduction}

Movements of asset prices are often subject to band restrictions. In the case of exchange rates, these bands characterize every system of fixed exchange rates-from the international gold standard onwards. The upper and lower limits of fluctuation of currencies' exchange rates are in many instances announced publicty: for cxample, under the Bretton Woods regime the price of dollars in terms of member currencies was restricted within a band of 1 percent on either side of central parities; under the European Monetary System (EMS) bilateral exchange rales of most currencies are allowed to fluctuate within bands of 2.25 percent on either side of central parities.

The theoretical implications of target zones were not studied until recently. See, for example, Krugman (1988), Bertola and Caballero (1989), Bertola and Svensson (1990), Svensson (1991a), and Lindberg and Söderlind (1991). These studies find, among other things, the following consequences of a target zone: (1) The exchange rate distribution is bounded on both the upper and lower sides. (2) The urconditional distribution depends on the lype of monetary intervention policy involved and the structural relations assumed. (3) The conditionai distribution is heteroskedastic. (4) The intercst rate differential as a measure of expected realignment is imprecise-

Following the theoretical literature, a number of empirical papers have appeared, aiming at estimating the unconditional distributions of exchange rates and testing the credibility of target zones. Among these, see in particular Flood, Rose and Mathieson (1990), Giovannini (1990), Lindberg, Svensson and Söderlind (1991), Rose and Svensson (1991) and Svensson (1991b,c). Typically, they compare interest-rate differentials, which are used as proxies of expected exchange-rate changes, with information about the exchange-rate bands. Such comparisons lead to propositions about the credibility of the bands.

Two challenging problems remain in the empirical studies of exchange rates under the target zones. The first is the presence of the band restriction on the exchange rates. Since rational agents should include the announced band as part of their information set, it is important for the econometrician to explicitly take llat into 
account. The second bas to do with the difliculty in estimaling the exchange rate distribution. Since the distribution varies with the intervention policies assumed, and since the theoretical models have closed form solutions for only a few simplified policy rules, it is difficult to estimate a distribution corresponding to the true underlying policy and model structure.

In what follows we present a nethod for estimating expected exchange rates within Larget zone bands and a method for estimating the unconditional distribution of exclange rates which are not ronditional on any fundamental model of exchange rates. The spirit of our test derives lrom the projection-equation methods to estimate expectations, as discussed, for example, by Abel and Mishkin (1983). The advantage of this methodology is its generality: projection equations are often alternatives in tests of structural models. We show, however, that in the case of target zones the projection-equation methodology of estinating expectations has to be modified in an important way, to account for the presence of target zones.

The general test procedure followed in this paper is like that of Rose and Svensson (1991), Svensson (1991c) and Lindberg, Svensson and Söderliad (1991). Unlike these at:Lhors, however, we explicity account for the distributional implications of target zones. We show that failing to do so leads to estimation bias and develop a new econometric procedurc that is unbiased and asymptotically efficient. Our procedure docs not hinge on special assumption on the distribution of the projection error, but can allow for a lazge lamily of distributions which can approximate those implied by the theoretical models. To illustrate our empirical methodology, we apply it two datasets taken from different exchangerate regimes, including the Bretton Woods regime and European Monetary System.

The rest of the paper is organized as follows. Section 2 develops a method of estimating expected exchange rates under target zones and applies the method to testing the credibility of exchange rate regimes. Section 3 presents a method to estimate the urconditional distributions and applies it to the data. Finaliy, section 3 contains a few concluding remarks. 


\section{Estimating Expected Exchange Rates within Band and Testing the Credibility Exchange Rate Regimes}

\subsection{The Estimation}

Following Svensson ( $1991 \mathrm{a})$, we decompose the log exchange rate $\left(s_{t}\right)$ into the summation of the log central parity $\left(c_{t}\right)$ and the log percentage deviation from the central parity $\left(I_{1}\right)$, the latter is restricted by the fluctuation band $\left(-L \leq x_{t} \leq L\right)$. We call it the exchange rate within band. Our task in this section is to estimate the expected exchange rate within band.

Convertional estimation methods are developed for random variables that are unbounded and, preferably, nornally distributed. To deal with the bounded exchange rates with unknown distribution, we first transform the random variable into an unbounded one, and then employ estimation methods that do not rely on distributional assumptions.

We now transform the expected exchange rate within band, $x_{i}$, into a new variable $y_{i}:$

$$
y_{t} \equiv \ln \left(\frac{L+x_{t}}{L-x_{t}}\right), \quad-L \leq x_{t} \leq L .
$$

We adopt the above transiormation on both technical and conceptual grounds. Technically, the range of the transformed variable $y_{4}^{*}$ is unconstrained, we can, in principle, use conventional lechniques to estimate the parameters. Conceptually, as we mentioned before, we need to take the band restriction into account since it is an essential part of the agents' information set. Our definition of $y_{t}^{\text {E }}$ iurns out to be a measure of exchange rate inside the band that takes into account the presence of both bounds. To see this, consider the terms $L+x_{t}$ and $L-x_{t}$. The former is the distance between the exchange rate inside the band and the lower limit of the band, and the latter is the distance between the exchange rate inside the band and the upper limit of the band. The ratio of the two terms is therefore a mensure of the position of the exchange rate relative to the upper and lower limits of the band. Therefore the band information is naturally embedded in our transformed variable $y_{t}^{*}$ (the log of the ratio). 
Foliowing the projection melhodology, we propose the following linear projection equation for $y_{!}^{*}$ :

$$
y_{t}^{*}=z_{t}^{\prime} \beta+u_{t}
$$

where $z_{1}$ is the vector of information variables. $\beta$ is a vector of parameters to be estimated. and $u_{t}$ is contemporaricously independent of $z_{t}^{\prime}$.

In estimating cxpected exchange rates within bands the projection horizon is usually longer than the sampling intervals of the data. To make full use of the sample information we follow the strategy developed in llansen and Hodrick (i980), Cumby, Huzinga and Obstfeld (1983), and Hansen (1982) to obtain consistent estimates of $\beta$ and its covariance matrix.' Following Svensson (1991c) we also use the Newey-West (1985) modification to account for the conditional heteroskedasticity.

The projection equation gives the estimate of the expectation of $y_{i}^{*}$ as $z_{t}^{\prime} \dot{\beta}$. To estimate the expected ralues for $x_{l}$, consider the reverse transformation:

$$
I_{l}=\frac{\exp \left(\frac{y_{i}^{i}-\tau}{\delta}\right)-1}{\exp \left(\frac{y_{i}^{i}-\tau}{\delta}\right)+1} L .
$$

Since $\hat{\beta}$ is asymptotically normal and efficient (See Hansen (1982)), and its covariance matrix $\left(\hat{V}_{\beta}\right)$ can be calculated using the Newey-West (1982) procedure, it follows that $y_{i}$ is asymptotically normal with mean $z_{t} \hat{\beta}$ and variance $z_{1}^{\prime} \hat{V}_{\beta} z_{t}+e^{\prime} e / T$, where $e$ is the vector of rcsidual terms and $T$ is the sample size. We can then obtain the asymptotic density function for $x_{\ell}$ using the change-of-variables procedure:

$$
f\left(x_{1}\right)=\frac{2 L}{L^{2}-x^{2}} \phi\left(\frac{\ln \frac{L+x_{1}}{L-x_{1}}-z_{t} \hat{\beta}}{\sqrt{z_{t}^{\prime} \hat{V}_{\beta}^{\prime} z_{t}+e^{I} e / T}}\right),
$$

where $\phi(\cdot)$ is the standard normal density function. The expected value of $x_{!}$is given by

$$
\hat{\tau}_{t}=\int_{-L}^{L} x_{t} f\left(x_{t}\right) d x_{t}
$$

\footnotetext{
'The usual GLS and maximum likelihood estinators are inconsistent in the case of autocorrelated srrors, if the independent variables are not economelrically exogenous (See Cumby and Huizinga, 1990). In the case of excliange cate models, most information variables are predetermined rather than exogenous.
} 
The $95 \%$ confidence intervals can then be numerically calculated for each $\dot{\boldsymbol{x}}_{\mathrm{t}}$. Due to conditional heteroskedasticity, the confidence interval is asymmetric. So its upper and lower bounds need to be computed separately. Specifically, the upper bound at time $t, B_{t}^{U}$, can be computed numerically as the solution to the following nonlinear equation:

$$
\int_{x_{t}}^{B_{t}^{U}} f\left(x_{t}\right) d x_{t}=47.5 \% .
$$

Similarly, the lower bound $B_{t}^{L}$ can be obtained by solving

$$
\int_{B_{l}^{L}}^{\dot{x}_{t}} f\left(x_{t}\right) d x_{t}=47.5 \% .
$$

By construction $\bar{x}_{1}$ and its confidence interval can only fall between $-L$ and $L$.

The advantage of the above method is its simplicity and generality. It does not assume any structural relations between the exchange rate and the fundamentals, ${ }^{2}$ ratlier it relies on the projection equation to extract information useful in predicting exchange rates. It does not impose restrictions on the distribution of the exchange rate. The band restriction, however, is explicitly imposed in a natural way.

\subsection{Comparison with Existing Estimation Methods}

One way to estimate the expected exchange rates within target zones is to use a fully specified model and numerically simulate the probability densities and compare the simulated moments with the empirical moments. This js known as the simulated method of moments (see Lindberg and Söderlind (1991)). The method is tied to the particular model structure. It gives accurate estimates of the model parameters if the model is the true description of the mechanism generating the data. If, however, the model is not a good approximation to the true exchange rate mechanism, either because of the difficulty in selecting proper fundamental variables or because of the oversimplified assumptions aboul the intervention policy, then the estimated exchange rates will be imprecise. In the latter case, our unconstrained method can often give improved estimation. Another commonly used procedure applies the OLS directly

\footnotetext{
${ }^{3}$ This is desirable due to the poor empirical performance of nearly all structural models for exchange rates.
} 
Lo the data within the band. The method is completely unconstrained: it is not only flexible in the choice of fundamentals and the distribution, bul also imposes no band restrictions on the exchange rates. The motivation for this meliod is that the OLS is robust to the distributional assumptions, so it slould be applicable to distributions of any shapes and forms, including the bounded distributions. However, this method is problemalic for the following reasons: the OLS requires the error term to be identically distributed and uncorrelated with the regressor. But when the dependent variable is subject to the band restriction, these conditions no longer hold. To see this, let the OLS regression equation be

$$
x_{t}=z_{t}^{\prime} \beta+e_{1}
$$

where by the assumption of the OLS, $e_{t}$ is an independently and identically distributed random variable with mean zero, and is uncorrelated with $z_{i}^{\prime}$. But the target zone restriction requires that

$$
-L \leq x_{t} \leq L,
$$

which implies

$$
-L-z_{t}^{\prime} \beta \leq e_{\mathrm{t}} \leq L-z_{t}^{\prime} \beta \text {. }
$$

As we can sec, the error term is regulated by the upper bound $\left(L-z_{t}^{\prime} \beta\right)$ and the lower bound $\left(-L-\alpha_{*}^{t} \beta\right.$ ), so its distribution depends on the value of the independent variable al time $t$, i.e., it is not identically distributed, and it is correlated with the regressor. Also the zero mean assumption does not hold in general. The OLS estimator is therefore biased.

The economic interpretation of these biases is simple: since the band restriction is part of the information set for the rational agents. the agents can exploit the information to predict future monetary interventions. For example, when the current exchange rale is too close to the upper limit, it can only be expected to move downward, and the agents know how much room (ilue lower limit) there is for the downward movement, if the target zone is credible. Therefore the band restrictions has to be imposed in the empirical estimation. Ignoring them introduces a correlation between information and surprises which is not exploited by agents if they use simple 
OLS projections, and therelore implies a deviation from the rational expectations hypothesis.

\subsection{An Empirical Illustration}

We now appiy the economelric methodology developed above to data from the European Monetary System and the Biretton Woods regime. The data are compiled as follows. For the Bretton Woods period, the end-of-month spot exchange rates are from the International Financial Statistics, the three month forward exchange margin (a proxy used to construct the interest rate differential) is obtained from Grubel (1966). For the EMS period, the monthly exchange rates are the last daily quote of each month from the data set compiled by Andrew Rose. ${ }^{3}$ The three-month interest rates data are from the international database currently maintained at the Federal Reserve Board. The money supply data for both the Bretton Woods and the EMS regimes are from the IFS tape. To focus on the target zone problem, we have adjusted the values of a lew large observations so that they lie inside the band.

While in the EMS fuctuation bands are 2.25 percent on either side of the central parity, under Bretton Woods they were only 1 percent on either side of the dollar parity." Hence the width of the Bretton Woods bands we study here is less than half the width of the EMS bands.

\subsubsection{Projection Equations}

We use various information variables to estimate the projection equations. Specifically, we use current $y_{t}^{*}$, its higher order terms, intercst rate differential (we use forward exchange margin is used as a proxy of interest rate differential for the Bretton Woods period), money supplies (for countries with monthly data available), and regime dummies corresponding to different central parities. The point estimation results are reported in Table 1 through 6.

\footnotetext{
${ }^{3}$ We thank Lars Svensson for having made available the EMS data set originally developed by Andy Roge. That data set is described in Flood, Rose and Mathitson (1990).

The implication is that bilateral fuctuation bands for non-dollar exchange rates were 4 percent wide.
} 
To compare our method with the conventional method, we also report the results of the conventional projection equation which ignores the band restrictions. Such unrestricted model regresses $x_{t+3}$ on $x_{1}$ and its higher order terms, and other in formation variables used in the constrained model.

Figures 1 througin 6 are the estimated $95 \%$ confidence intervals for expected ex change rates within band (with $47.5 \%$ confidence region on either side of lise estimates). The solid jines are the results our restricted model (with band restriction imposed via the transformation procedure), while the dotted lines are results of the convectional linear projection of $x_{1}$. As we can see, in the former case the estimated values and confidence intervals are all within the band, but in the latter case, we find many periods when the estimated values and confidence intervals lie outside the band, which is clearly inconsistent with the presence of the band. The problem is more serious during the Bretton Woods regime, when the band is narrower (1\%). Also, when the band restriclion is imposed, the confidence intervals are mostly asymmetric, which is a direct consequence of special form of the conditional density function under the target zones.

It is interesting to note that, under the band restriction, even when the projection error is large (e.g. the Belgian franc under the EMS), tine restricted confidence interval tends to fill the whole target zone but is bounded by the latter. This implies that even when the information sct is noisy the information about the band is stili exploited.

Svensson (1991c) lound mean reversion in the exchange rate within the band and show that the interest rate diftercntial needs to be adjusted for the expected rate of devaluation within the band to yield the correct expected devaluation. This is also confirmed in our empirical results: the adjustment on the interest rate differential is sizable in most cases. The coefficient for the current $y_{t}^{*}$ is, like the case of unrestricted models, usually far less than 1 , even though $y_{i}^{*}$ it is by definition unrestricted has a larger range of nuctuations in the data. This implies the fluctuations within a. given target zone are transitory, mean reversion processes. This implies that the central hank allows temporary fluctuations within the band while deferring long-run adjustment to later rcalignment of central parity. 


\subsubsection{Testing the Credibility of Exchange Rate Regimes}

Rose and Svensson (i991) and Svelsson (1991c) formulate a method to test the credibility of exchange rate regimes. The essence of the test is to compare the estimated expected exchange rate devaluation with the announced official target, and see if they ate significantly different. The expected exchange rate devaluation is show to be the interest rate differential adjusted for the expected depreciation within band, i.e.,

$$
\begin{aligned}
& E_{l} \Delta c_{t}+p_{t}\left[E_{t}\left(x_{t+1} \mid \text { realignment }\right)-E_{t}\left(x_{t+1} \mid \text { no realignment }\right)\right] \\
& =i_{t}-i_{i}^{*}-E_{t}\left(\Delta x_{t} \mid \text { no realignment }\right)
\end{aligned}
$$

where $i_{t}$ and $i_{i}^{*}$ are the domestic and foreign interests respectively. The lelt-hand side of (5) can be interpreted as the expected rate of devaluation: it is the combination of the expected change in the central parity and the expected change in the deviation from the central parily. See Rose and Svensson (1991) for more discussions.

$A$ test of credibility of the target zone is a test that the leit-hand side of equation (5) is equal to zero. It is constructed as follows: First, estimate $E_{t}\left(\Delta x_{t}\right.$ )no realignment) and compute its confidence interval. Then subtract the confidence interval from the interest rate differential $i-i^{*}$. At any time $t$, we conclude that the band is credible if zero (which corresponds to the central parity) is contained in the resuiting confidence interval.

Figures $i$ to 12 contain the results of the credibility tests. They report the estimated $95 \%$ confidence intervals for the expected devaluation three month ahead. Again, we report results of both the restricted model (solid lines) and unrestricted model (dotted lines). Figures 7 and 8 show the case of the pound sterling and the Deutsche mark under the Bretton Woods system. The confidence intervals given by the unconstrained model are much wider than those implied by the constrained model. As a result, there are many periods when credibility is clearly rejected by the restricted model but not by the unconstrained model. 'T!is has to do with the erroneous ostimates of confidence intervals for the expected future exchange rates (see figures 1 and 2). For the EMS period (figures 9 to 12), the difference of confidence intervals are evident, but less striking than the case of the Bretton Woods period, 
suggesting that the band restrictions are less severe when the band is vider (2.25\% under the EMS). Also, under the EMS, frequent rejections of credibihity occur for the Belgian Frane (figure 9), the Danish krona (figure 10), and the French franc (figure 11), and the rejections tend to occur at roughly the samc time, suggesling lhat most credibility problems are a result of common siocks faced by these countries. The case of Dutch guilder is shown in figure 12. As we know, the guilder was kept weil inside the target zone, and the fuctuations were very small except for the beginning part of the EMS period. Nol surprisingly, we find very few rejections of credibility for the guilder.

\section{Estimating the Unconditional Distributions}

\subsection{The Methodology}

In this section we discuss a way to estimate the unconditional distribution of exchange rates under the target zones. Theoretical target zone models (e.g., Krugman (1991) and Lindberg and Söderind (1991)) are constructed on the basis of the standard asset price modei for the exchange rate:

$$
s(t)=f(t)+\alpha d E[s(t)] / d t,
$$

which states that the current exchange rate depends on its lundamental value $f(t)$ and the expected luture exchange rate. The central bank intervenes by altering such fundamentals as the money supply in accordance with the target zone policy. Krugman postulates an infinitesimal intervention policy which occurs only at the limits of the larget zone ${ }^{5}$ and shows that the asymptotic (unconditional) distribution of the exchange rate is U-shaped (bimodal). See Flood, Rose and Mathieson (1990) for more discussions. Lindberg and Sóderlind consider the case of intra-rnarginal intervention with the degree of intervention being proportional to the deviation of money supply from its targeted level. They conclude that the asymptotic distribution of the exchange rate is beli-shaped. The bell-shape is consistent with the notion of

\footnotetext{
${ }^{5}$ The policy leads lo a regulated Brownian motion specification for $f(t)$.

${ }^{6}$ This specification leads to a regulated Ornstein-Uhienbeck process [or $f(t)$.
} 
mean reversion due to the nature of the assumed intervenition poilicy. In botll cases the distributions are bounded (truncated) by the targeted exchange rate band.

The target zone models have closed form solutions only lor a few simplified specifications of intervention policies such as those mentioned above. The models themselves usually do not address the question of what the economic fundamentals should be inciuded in determining $f(t)$. It is conceivable that other specifications of the fundamentals and of the intervention policies will yield different forms of distributions.

The above discussions suggest that in formulating a general estimation procedure, one should explicitly take into account the band restriction, but at the same time should be flexible on the selection of the fundamental variables and on the assumption about the distributional forms. In this spirit, Flood, Rose and Mathieson (1990) plot the data írequency charts for various currencies. The disadvantage of that eye-balling method is that it is not a formal estimation. Here we propose a way to parameterize and estimate the density curves under target zone restrictions.

The underlying density function is not known. However, there is a rich tradition in probability studies to mimic different shapes of density curves using a limited number of parameters. A classical example is the Pierson family of distributions, which can mimic most known distributions. In our particular problem, we require a mimicking system that captures different shapes of density curves for data with upper and lower bounds. Johnson (1949) and Johnson and Kotz (1970) cievelop a parameterization system (known as the $S_{B}$ system) for the bounded data. They use the standard normal density function as a basic building block, together with a transformation function with only four parameters, two for the shaping function, and two for the lower and upper bounds, to describe a rich variety of distributions. The same methodology is followed in the Box-Cox transformation procedure. Following this methodology, we propose the following lransformation

$$
y_{t} \equiv \gamma+\delta \ln \left(\frac{L+x_{t}}{L-x_{t}}\right), \quad-L \leq x_{t} \leq L,
$$


where $L$ is the half-width of the symmetric band. ${ }^{7}$ The transformed variable $y_{t}$ is assumed to be $N(0,1)$. As sucl, the distribution of $x_{t}$ given $L$ is determined uniquely by the two transformation parameters $\gamma$ and $\delta$. With different combinations of $\gamma$ and $\delta$, one can numerically simulate almost ali relevant densily curves for the random variable $x_{t}$ with lower and upper bounds. The density curves can take the documented U-shape and bell shape, as well as other shapes that are not documented in previous literature. When $\gamma=0$ the densily curve is symmetric. The normal distribution corresponds to the case $\delta \rightarrow \infty$.

Maximum likelihood is a natural way to estimate the density curve without imposing prior structural restrictions. Let $\phi(y)$ be the density function for the standard normal distribution, then by the change-of-variables rule the density lunction for $x_{t}$ is

$$
f(x)=J \phi\left(\gamma+\delta \ln \frac{L+x}{L-x}\right)
$$

The Jacobian $J$ is given by

$$
\delta \frac{2 L}{L^{2}-x^{2}}
$$

The log likelihood function is

$$
I=\sum_{T} \ln J_{t}+\sum_{T} \ln \phi\left(\gamma+\delta \ln \frac{L+x_{t}}{L-x_{i}}\right)
$$

Maximizing the likelihood function / we can obtain estimates of $\gamma$ and $\delta$. The density curve can be numerically generated for the estimated parameters. We can then examine what kind of intervention policy is more likely to be consistent with the exchange rate data, as we will demonstrate in the empirical section.

\subsection{Empirical Results}

Table 7 reports maximum-likelihood estimates of the parameters $\gamma$ and $\delta$ which characterize the shape of the unconditional distribution of $x$. As we argued in section 4 , a value of $\gamma$ close to zero indicates that the estimated unconditional distribution of $x$ is approximately symmetric. A value o[ $\delta$ close to zero implies a $U$-shaped unconditional distribution, while when $\delta$ gets large the distribution approximates a bell-shape.

\footnotetext{
'The proçeduce can be extended easily to asymmetric bands.
} 
For the Bretton Woods sample, ${ }^{8}$ the unconditional distribution of $x$ lor the pound sterling is symmetric ( $\gamma$ insignificantly different from zero), and is between the bimodal and the bell shape, as shown in figure 9. Figure 10 shows the case of the Deutsche mark during the Bretton Woods period. The distribution is an asymmetric $\mathrm{U}$, with most of the probability mass concentrated by the lower edge of the fiuctuation band (stronger DM).

Figures 11 to 44 report the plots of the estimated unconditional distribution for $x$ during the EMS for the Belgian franc, Danish krona, French franc and Dutch guilder, respectively. In the case of the EMS the U-shaped distribution is prevalent, while the bell shape is observed, interestingly, only in the case of the guilder.

As we know, the $\mathrm{U}$-shaped distribution is a prediction of the Krugman (1990) model, in which the monetary intervention occurs on the edges of the band, while the bell-shaped distribution (e.g., the case of the guilder) is consistent with the type of intra-marginal intervention policy described by Lindberg and Söderlind (1991). The asymmetry in most of the distributions implies that the central bank may be actually defending an implicit upper or lower bound. The distribution of the pound is an intermediate case between the bell shape and the U shape, which may imply a monetary policy that lies in between the marginal and intra-marginal interventions.

Recall that the transformed variable $y$ differs from our previously defined $y^{\text {* only }}$ by the parameters $\gamma$ and $\delta$, which further change the mean and variance of the density curve. The normal assumption is not a strong restriction to the original variable $I$, but is a convenient tool to simulate the underlying distribution. In the conditional projection estimations, we did not impose the normal distribulion assumption, however, with our estimated $\hat{\beta}, y^{-}$is asymptotically normal.

\section{Concluding Remarks}

This paper has developed techniques to estimate the exchange rate distributions and the expected clianges in exchange rates when the latler are constrained within a given band. The techniques have the advantage of not relying on a structural model, and

\footnotetext{
${ }^{3}$ We used the daily sample from the Rose datasel
} 
not inposing any particular shape to the unconditional distribution of the exchange rate, while at the same time explicitly exploiting the information contained by the presence of Euctuation limits.

Our empirical results stow that the presence of the band can indeed affect the estimates of the expected future exchange rates and the credibility tests. The effect is large when the band is tight. It is theretore important to take the band restrictions into account whenever the band restriction is likely to be binding.

The empirical resuits also show that the unconditional distributions of exchange rates can take several different shapes, which may correspond to possibly widely different monetary and exchange-rate intervention policies. The possibility of widely diferent models of fundamental determinants of exchange rates within luctuation bands underscores the use of atheoretical projection equations like those developed in this paper. 


\section{References}

Abel, A. and F.S. Mishkin (1983): "An Integrated View of Tests of Rationality, Market Efficiency and Short-Run Neutrality of Monetary Policy," Journal of Monetary Economics, 9, January, pp. 3-24.

Bertola, G. and R.J. Caballero (1989): "Target Zones and Realignments," Working Paper, Princeton University.

Bertola, G. and L.E.O. Svensson (1990): "Target Zones and Realignments," CEPR Working Paper n.398.

Cumby, R.E. and J. Huizinga (1990): "Testing the Autocorrelation Structure of Disturbances in Ordinary Least Squares and Instrumental Variables Regressions," NBER Technical Working Paper No. 92.

Cumby, R.E. and J. Huizinga and Obstfeld (1983): "Two-Step Two-Stage Least Squares Estimation in Models with Rational Expectations," Journal of Econometrics, $21,333-355$.

Flood, R.P. A.K. Rose and D.J. Mathieson (1990): "An Empirical Exploration of Exchange-Rate Target Zones," Carnegie-Rochester Conference Series on Public Policy lorthcoming.

Giovannini, A. (1990): "European Monetary Reform: Progress and Prospects," Brookings Papers on Economic Activily 2, pp, 217-291.

Grubel H.G. (1966): "Forward Exchange Rates, Speculation, and the International Flow of Capital," Stanford, CA: Stanford University Press.

Hansen, L.P. (1982): "Large Sample Properties of Generalized Methods of Moments Estimators," Econometrica, 50, 1029-1054. 
Hansen, L.P. and R.J. Hodrick (1980): "Forward Exchange Rates as Optimal Predictors of Future Spol Rates: An Econometric Anaiysis," Journal of Political Economy, 88, 829-853.

Johnson, N.L. (1949): "System of Frequency Curves Generated by Melhods of Trauslation," Biometrika, 36, 149-176.

Johnson, N.L., and S. Kotz (1970): Continuous Univariate Distributions-1, Houghton Mifflin Company: Boston.

Krugman, P. (i988): "Target Zones and Exchange-Rate Dynamics," NBER working paper No. 2481, Quarterly Journal of Economics, forthcoming.

Lindberg, H., L.E.O. Svensson, P. Söderlind, (1991): "Devaluation Expectations: The Swedish firona 1982-1991," mimeo, IIES, Stockholm.

Lindberg, H., and P. Söderlind, (1991): "Target Zone Models and the Intervention. Policy: The Swedish Case," Mimeo, Sveriges Riskbank and IIES, Stockholm.

Newey, W.K. and K.D. West (1985): "A Simple, Positive Definite, Heteroscedasticity and Autocorrelation Consistent Covariance Matrix," Econometrica, 55, 703-708.

Rose, A.K. and L.E.O. Svensson (1991): "Expected and Predicted Realignments: The FF/DM Exchange Rate During the EMS," IIES Seminar Paper n. 48.5.

Svensson, L.E.O. (1991a): "Target Zones and Interest-Rate Varjability" Journal of International Economics, 31. pp. 27-54.

Svensson, L.E.O. (199Lb): "The Simplest Test of Target Zone Credibility" IMF Staff Papers 38, pp. 655-665.

Svensson, L.E.O. (1991c): "Assessing Target-Zone Credibility: Mean Reversion and Devaluation Expectations in the EMS," IIES Seminar Paper n. 493. 


\section{TABLE 1}

Estimation of Expected Future Exchange Rate within Band:

BP/USS under the Bretton Woods System

Projection Equation: $y_{i+3}^{*}=\sum_{i=1}^{2} \alpha_{i} d_{i}+\sum_{j=1}^{4} \beta_{j} \Sigma_{j, t}+u_{t}$.

\begin{tabular}{|c|c|c|c|}
\hline Variable & Definition & Coefficient* & Std Error ${ }^{* x}$ \\
\hline$d_{1}$ & Regime dummy $55: 07-67: 10$ & 0.0389 & 0.1208 \\
\hline$d_{2}$ & Regime dummy 67:11-7I:05 & 0.5732 & 0.4273 \\
\hline$=1$ & $y_{t}^{*}$ & 0.4609 & 0.1135 \\
\hline$z_{2}$ & Forward exchange margin & -0.4369 & 0.7763 \\
\hline 53 & $y_{t}^{-2}$ & -0.0794 & 0.1801 \\
\hline$\approx 4$ & $y_{t}^{-3}$ & -0.0095 & 0.0141 \\
\hline \multicolumn{4}{|c|}{ Diagnostics } \\
\hline & Number of observations & 170 & \\
\hline & Standard Error & 1.204 & \\
\hline & $R$-squared & 0.128 & \\
\hline & $F(6,164)$ & 4.032 & \\
\hline & Number of autocovariances & 2 & \\
\hline & Autocorrelation of errors: & & \\
\hline & One period & 0.351 & \\
\hline & Last period & 0.123 & \\
\hline
\end{tabular}

*The Coefficients are estimated using OLS.

" The standard errors of coefficients are the GMM estimates adjusted for heteroskedasticity using the Newey-West method. 
TABLE 2

Estimation of Expected Future Exchange Rate within Band:

DM/USS under the Bretton Woods System

Projection Equation: $y_{i+3}^{-}=\sum_{i=1}^{3} \alpha_{i} d_{i}+\sum_{j=1}^{5} \beta_{j} z_{j, 1}+u_{1}$.

\begin{tabular}{|c|c|c|c|}
\hline Variable & Definition & Coefficient ${ }^{*}$ & Std Error** \\
\hline $\begin{array}{l}d_{1} \\
d_{2} \\
d_{3} \\
z_{1} \\
z_{2} \\
z_{3} \\
z_{4} \\
=5\end{array}$ & $\begin{array}{c}\text { Regime dummy } 55: 07-61: 02 \\
\text { Regime dummy } 61: 03-69: 09 \\
\text { Regime dummy } 69: 10-\overline{1} 1: 05 \\
\qquad y_{i}^{:} \\
\text {Forward exchange margin } \\
\text { Relative money supply } \\
\qquad \begin{array}{c}y_{l}^{-2} \\
y_{t}^{-3}\end{array}\end{array}$ & $\begin{array}{r}-3.1024 \\
-2.1362 \\
-3.0585 \\
0.6043 \\
-0.3347 \\
-1.9303 \\
0.0765 \\
-0.0245\end{array}$ & $\begin{array}{l}1.0631 \\
0.8148 \\
0.8641 \\
0.1221 \\
0.4375 \\
0.7836 \\
0.1116 \\
0.0184\end{array}$ \\
\hline \multicolumn{4}{|c|}{ Diagnostics } \\
\hline & $\begin{array}{l}\text { Number of observations } \\
\text { Standard Error } \\
R \text {-squared } \\
F(8,162) \\
\text { Number of autocovariances } \\
\text { Autocorrelation of errors: } \\
\text { One period } \\
\text { Last period }\end{array}$ & $\begin{array}{r}170 \\
0.889 \\
0.381 \\
26.695 \\
2\end{array}$ & \\
\hline
\end{tabular}

*The Coefficients are cstimated using OLS.

- The slandard errors of coefficients are the GMM estimates adjusted for heteroskedasticity using the Newey- West method. 
TABLE 3

Estimation of Expected Future Exchange Rate within Band:

BF/DM under the EMS

Projection Equation: $y_{i+3}^{*}=\sum_{i=1}^{s} \alpha_{i} d_{i}+\sum_{j=1}^{q} \beta_{j} z_{j, t}+u_{i}$.

\begin{tabular}{|c|c|c|c|}
\hline Variable & Definition & Coefficient* & Std Error** \\
\hline$d_{1}$ & Regime dumny $79: 04-79: 08$ & 0.8942 & 0.6819 \\
\hline$d_{3}$ & Regime dummy $79: 09-81: 09$ & 0.7995 & 0.4562 \\
\hline$d_{3}$ & Regime dummy 81:10-82:01 & 3.1896 & 1.5007 \\
\hline$d_{4}$ & Regitne dummy 82:02-82:05 & 1.4922 & 1.7202 \\
\hline$d_{s}$ & Regime dummy 82:06-83:02 & 1.7218 & 1.0455 \\
\hline$d_{6}$ & Regime dummy 83:03-86:03 & 1.2145 & 0.5388 \\
\hline$d$ & Regime dummy 86:04-86:12 & -0.2546 & 0.7503 \\
\hline$d a$ & Regime dummy 87:01-90:04 & 0.6412 & 0.3842 \\
\hline$=1$ & $y *_{i}$ & 0.6587 & 0.4965 \\
\hline$=2$ & $i-i^{*}$ & 0.0226 & 0.0383 \\
\hline$=3$ & $y_{t}^{-2}$ & -0.1169 & 0.2473 \\
\hline$=4$ & $y_{i}^{-3}$ & 0.0026 & 0.0254 \\
\hline \multicolumn{4}{|c|}{ Diagnostics } \\
\hline & Number of observations & 130 & \\
\hline & Standard Error & 1.867 & \\
\hline & $R$-squared & 0.094 & \\
\hline & $F(12,118)$ & 8.589 & \\
\hline & Number of autocovariances & 2 & \\
\hline & Autocorrelation of errors: & & \\
\hline & One period & 0.351 & \\
\hline & Last period & 0.123 & \\
\hline
\end{tabular}

-The Coefficients are estimated using OLS.

**The standard errors of coefficients are the GMM estimates adjusted for heteroskedasticity using the Newey-West method. 
TABLE 4

Estimation of Expected Future Exchange Rate within Band:

DK/DM under the EMS

Projection Equation: $y_{i+3}^{-}=\sum_{i=1}^{9} \alpha_{i} d_{i}+\sum_{j=1}^{5} \beta_{j} z_{j+2}+u_{1}$.

\begin{tabular}{|c|c|c|c|}
\hline Variable & Definition & Coeficient* & Sid Error ${ }^{* *}$ \\
\hline$d_{1}$ & Regime dummy $79: 04-79: 08$ & 1.7287 & 2.1743 \\
\hline$d_{2}$ & Regime dumny $79: 09-79: 10$ & {$[.8242$} & 1.8376 \\
\hline$d_{3}$ & Regime dummy $59: 11-81: 09$ & 0.1006 & 1.8292 \\
\hline$d_{4}$ & Regime dummy $81: 10-82: 01$ & 0.0035 & $\$ .5009$ \\
\hline$d_{5}$ & Regime dummy 82:02-82:05 & -0.4193 & 1.5957 \\
\hline$d_{8}$ & Regime dumny 82:06-83:02 & 0.2743 & 1.6487 \\
\hline$d_{T}$ & Regime dummy 83:03-86:03 & 0.5394 & 1.1185 \\
\hline$d_{5}$ & Regime dummy 86:04-86:12 & 2.1835 & 1.1412 \\
\hline$d_{9}$ & Regime dumrny 87:01-90:04 & 1.8676 & 0.8238 \\
\hline$z_{1}$ & $y_{i}^{i}$ & 0.2372 & 0.1256 \\
\hline$=2$ & $i-i$ & -0.3441 & 0.0924 \\
\hline$=3$ & Relative mortey supply & -1.5949 & 1.5583 \\
\hline$z_{1}$ & $y_{i}^{-2}$ & 0.0006 & 0.0198 \\
\hline$\Sigma_{5}$ & $y_{1}^{-3}$ & -0.0047 & 0.0045 \\
\hline \multicolumn{4}{|c|}{ Diagnostics } \\
\hline & Number of observations & 130 & \\
\hline & S;andard Error & 1.463 & \\
\hline & $R$-squared & 0.418 & \\
\hline & $F(14,116)$ & 6.503 & \\
\hline & Number ol autocovariances & 2 & \\
\hline \multicolumn{4}{|c|}{ Autocorrelation of errors: } \\
\hline & One period & 0.343 & \\
\hline & Last period & 0.117 & \\
\hline
\end{tabular}

-The Coefticients are estimated using OLS.

- The standard errors of coefficients are the GMM estimates adjusted for heteroskedasticity using the Newey-West method. 


\section{TABIE 5}

Estimation of Expected Future Exchange Rate within Band:

FF/DM under the EMS

Projection Equation: $y_{i+3}^{*}=\sum_{i=1}^{7} \alpha_{i} d_{i}+\sum_{j=1}^{4} \beta_{j} z_{j, t}+u_{t}$.

\begin{tabular}{|c|c|c|c|}
\hline Variable & Definition & Coefficient ${ }^{*}$ & Std Error ${ }^{* *}$ \\
\hline $\begin{array}{l}d_{1} \\
d_{2} \\
d_{3} \\
d_{1} \\
d_{5} \\
d_{3} \\
d_{7} \\
z_{1} \\
z_{3} \\
z_{3} \\
z_{1}\end{array}$ & $\begin{array}{c}\text { Regime dummy 79:04-79:08 } \\
\text { Regime dummy 79:09-81:09 } \\
\text { Regime dummy 81:10-82:05 } \\
\text { Regime dummy } 82: 06-83: 02 \\
\text { Regime dummy 83:03-86:03 } \\
\text { Regime dummy 86:04-86:12 } \\
\text { Regime dummy 87:01-90:04 } \\
\qquad y_{i}^{-} \\
\qquad i^{-2} \\
y_{i}^{-2} \\
y_{i}^{-3}\end{array}$ & $\begin{array}{r}1.2585 \\
0.3772 \\
2.0667 \\
1.7153 \\
1.4008 \\
1.1571 \\
1.4008 \\
0.3129 \\
-0.2670 \\
0.0758 \\
0.0111\end{array}$ & $\begin{array}{l}0.4132 \\
0.5297 \\
0.7838 \\
0.9060 \\
0.4066 \\
0.3852 \\
0.2960 \\
0.1402 \\
0.0624 \\
0.0523 \\
0.0066\end{array}$ \\
\hline \multicolumn{4}{|c|}{ Diagnostics } \\
\hline & $\begin{array}{l}\text { Number of observations } \\
\text { Standard Error } \\
R \text {-squared } \\
F(11,119) \\
\text { Number of autocovariances } \\
\text { Autocorrelation of errors: } \\
\text { One period } \\
\text { Last period }\end{array}$ & $\begin{array}{r}.30 \\
1.337 \\
0.421 \\
8.367 \\
2 \\
0.368 \\
0.136\end{array}$ & \\
\hline
\end{tabular}

-The Coefficients are estimated using OLS.

m=The standard errors of coefficients are the GMM estimates adjusted for heteroskedasticity using the Newey-West method. 
TABLE 6

- Estimation of Expected Future Exchange Rate within Band:

$$
\text { NG/DM under the EMS }
$$

Projection Equation: $y_{i+3}^{*}=\sum_{i=1}^{3} \alpha_{i} d_{i}+\sum_{j=1}^{5} \beta_{j} z_{j, z}+u_{i}$.

\begin{tabular}{|c|c|c|c|}
\hline Variable & Definition & Coefficient* & Std Error** \\
\hline $\begin{array}{l}d_{1} \\
d_{2} \\
d_{3} \\
z_{1} \\
z_{2} \\
z_{3} \\
z_{4} \\
=5\end{array}$ & $\begin{array}{l}\text { Regime dumny } 79: 04-79: 08 \\
\text { Regime dumny 79:09-83:02 } \\
\text { Regime dumny 83:03-90:04 } \\
\qquad \begin{array}{c}y_{i}^{*} \\
i-i^{*}\end{array} \\
\text { Relative money supply } \\
\qquad y_{i}^{-2} \\
y_{i}^{-3}\end{array}$ & $\begin{array}{r}-2.5379 \\
-3.7415 \\
-3.0848 \\
0.4111 \\
-0.2434 \\
-2.6767 \\
0.0805 \\
0.0075\end{array}$ & $\begin{array}{l}2.0686 \\
1.9555 \\
1.8025 \\
0.3005 \\
0.0783 \\
1.4893 \\
0.1852 \\
0.0223\end{array}$ \\
\hline \multicolumn{4}{|c|}{ Diagnostics } \\
\hline & $\begin{array}{l}\text { Number of observations } \\
\text { Standard Error } \\
R \text {-squared } \\
F(8,122) \\
\text { Number of autocovariances } \\
\text { Autocorrelation of errors: } \\
\text { One period } \\
\text { Last period }\end{array}$ & $\begin{array}{r}130 \\
0.776 \\
0.291 \\
7.130 \\
2 \\
0.399 \\
0.159\end{array}$ & \\
\hline
\end{tabular}

*The Coeffcients are estimated using OLS.

* The standard errors of coefficients are the GMM estimates adjusted for heteroskedasticity using the Newey. West method. 
TABLE 7

Point Estimation of Parameters for the Unconditional Distributions

\begin{tabular}{c|c|c|c}
\hline Exchange Rate & Regime & $\gamma$ & $\delta$ \\
\hline BP/USS & Bretton Woods & $\begin{array}{c}0.009504 \\
(0.07603)\end{array}$ & $\begin{array}{c}0.794694 \\
(0.042723)\end{array}$ \\
\hline DM/USS & Bretion Woods & $\begin{array}{c}0.502989 \\
0.080694)\end{array}$ & $\begin{array}{c}0.633059 \\
(0.034034)\end{array}$ \\
\hline BF/DM & EMS & $\begin{array}{c}-0.85691 \\
(0.022309)\end{array}$ & $\begin{array}{c}0.585428 \\
(0.007898)\end{array}$ \\
\hline DK/DM & EMS & $\begin{array}{c}-0.154889 \\
(0.0191)\end{array}$ & $\begin{array}{c}0.530343 \\
0.00712)\end{array}$ \\
\hline FF/DM & EMS & $\begin{array}{c}0.103102 \\
(0.019176)\end{array}$ & $\begin{array}{c}0.572672 \\
(0.007745)\end{array}$ \\
\hline NG/DM & EMS & $\begin{array}{c}0.180468 \\
(0.019062)\end{array}$ & $\begin{array}{c}1.335625 \\
(0.017858)\end{array}$ \\
\hline
\end{tabular}

Note: Standard errors are reported in parentheses. 
Figure 1. $-95 \%$ contidence intervals for expected future exchange rates within baud: 3-month BP/US\$ under the Bretton Woods System

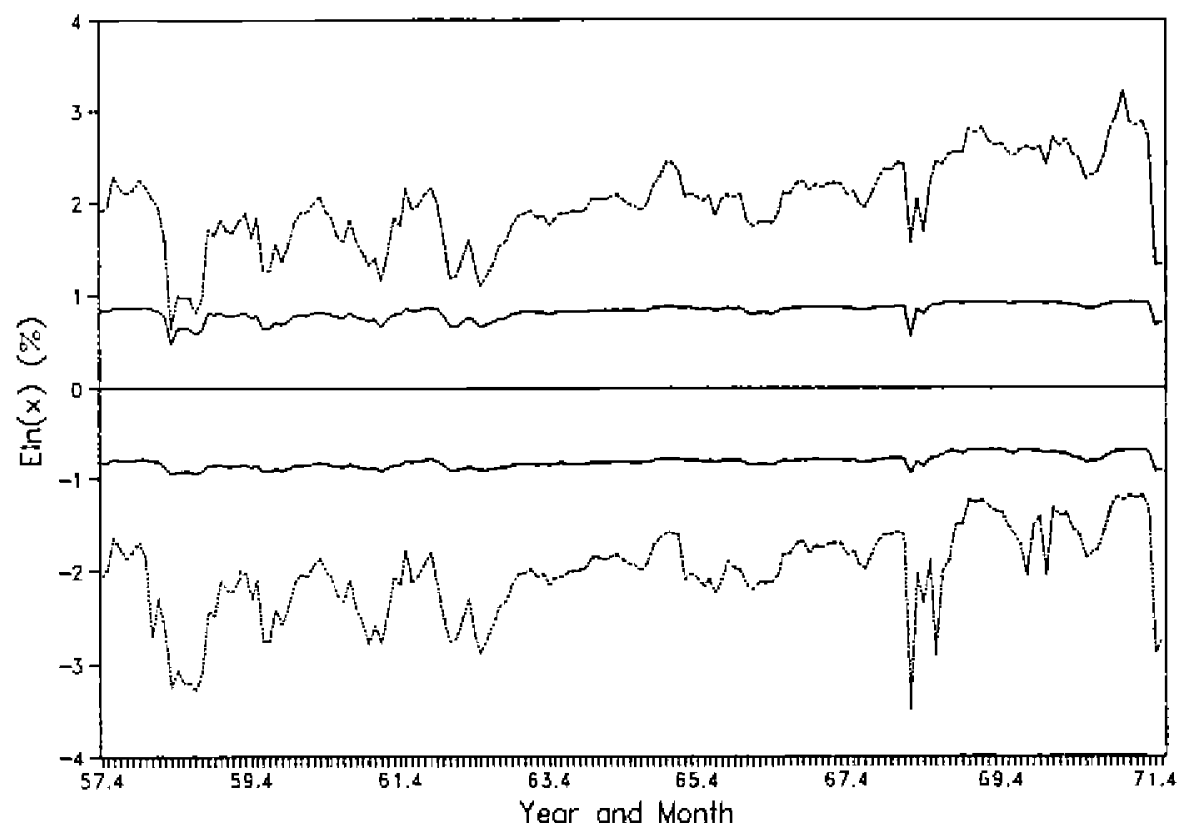

Uneonstrained Model $=$ Conslroined Hodel 
Figure 2.-95\% confidence intervals for expected future exchange rates within band: 3-month DM/USs under the Bretion Woods System

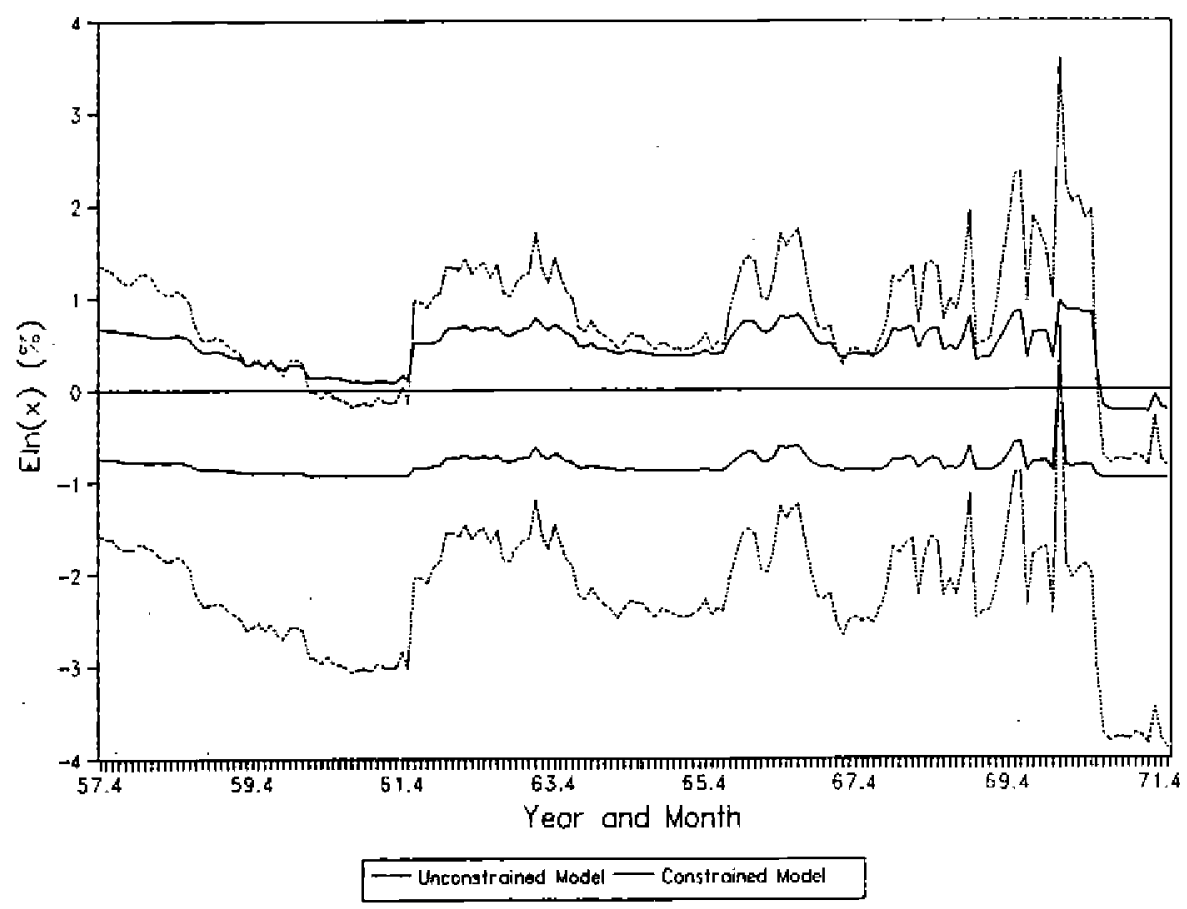


Figure $3,-95 \%$ confidence intervals for expected [ulure exchange rates within band: 3 -month BF/UM under the EMS

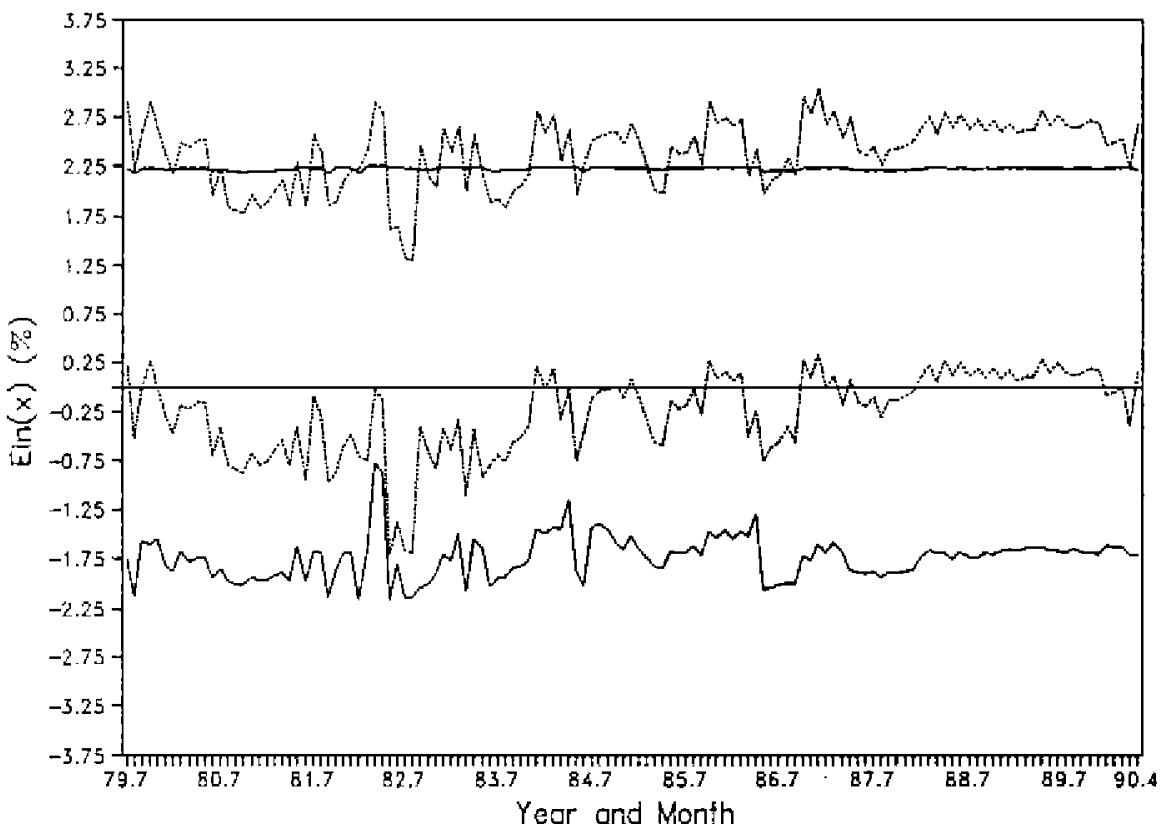

- Unconstrained Modiel Constrained Model 
Figure $4.65 \%$ confidence intervals for expected future exchange rates willin

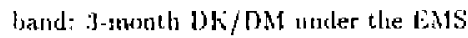

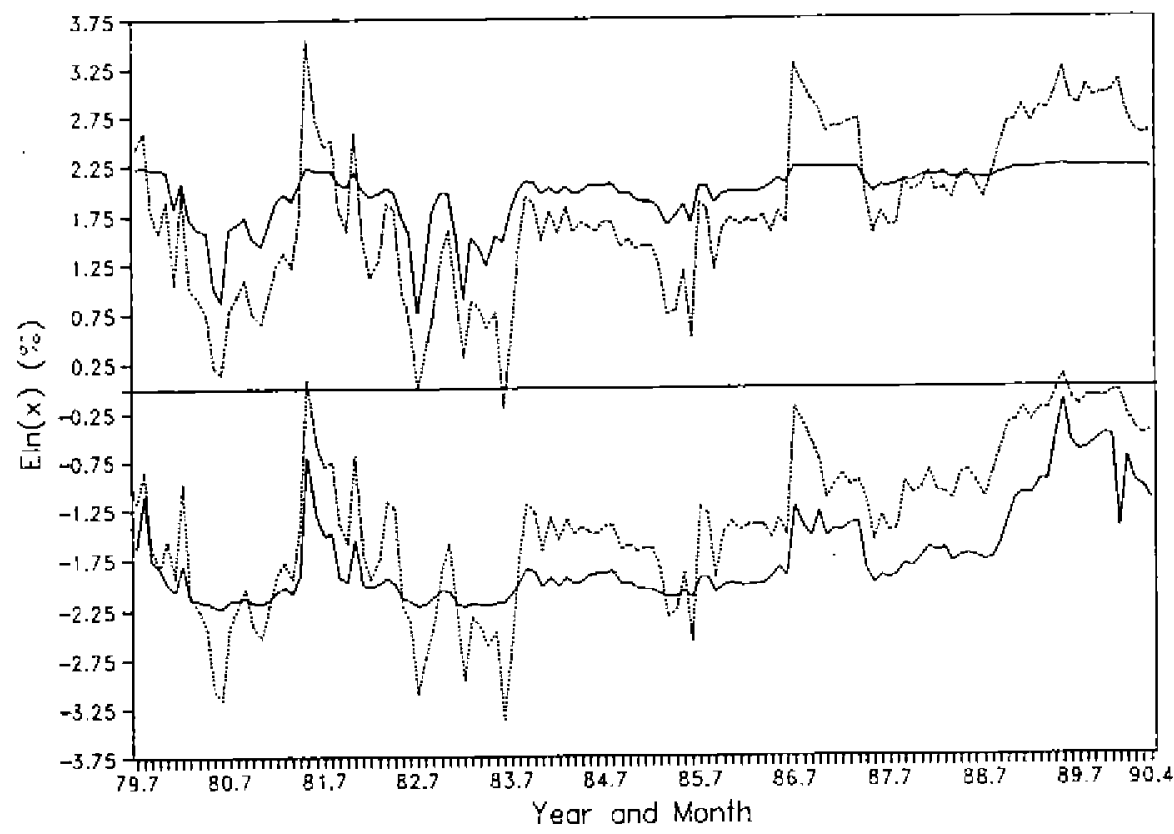

Unconstrained Model Constrained Model 
Fïgure 5.- $95 \%$ confidence intervals for expected future exclange rates within band: :3-month TF/DM under Lie EMS

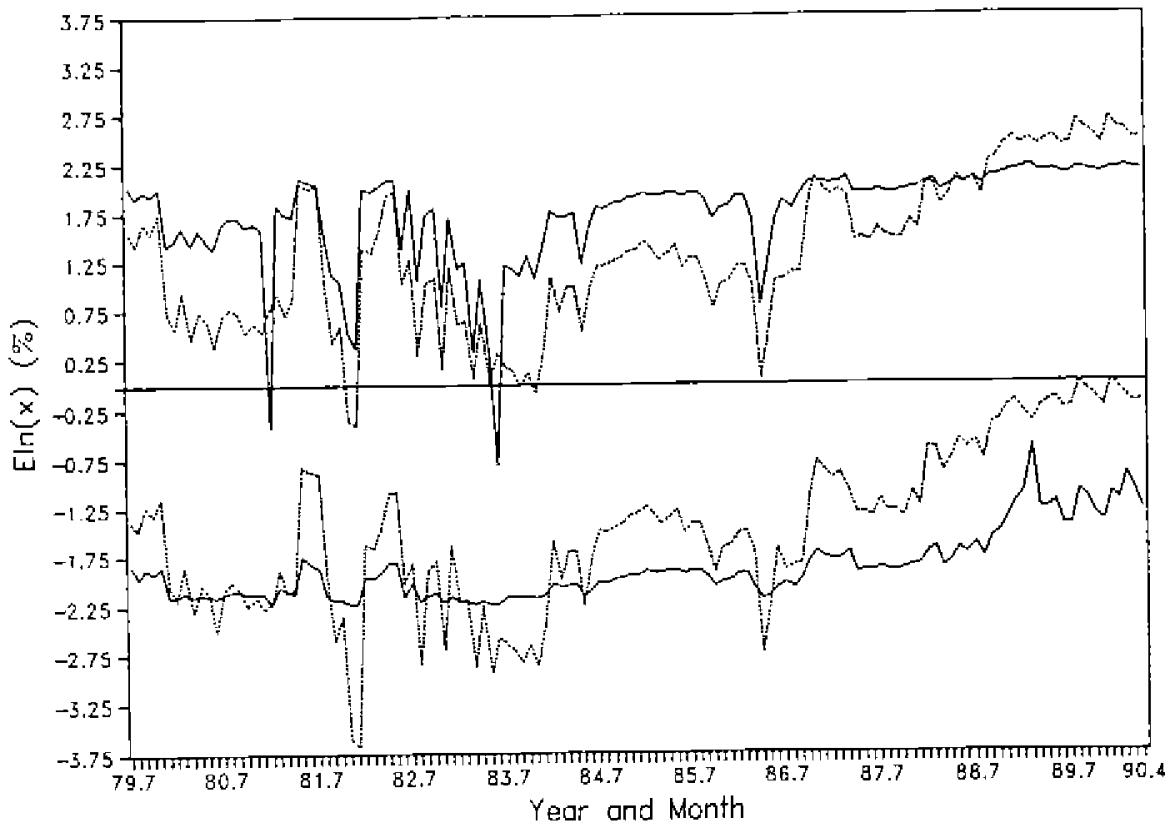

Unconstrained Model - Cansiroined Madel 
Pigure $6-95 \%$ confidence intervals for expected future exchange rates within hand: 3-nomth NG/DM under the EMS

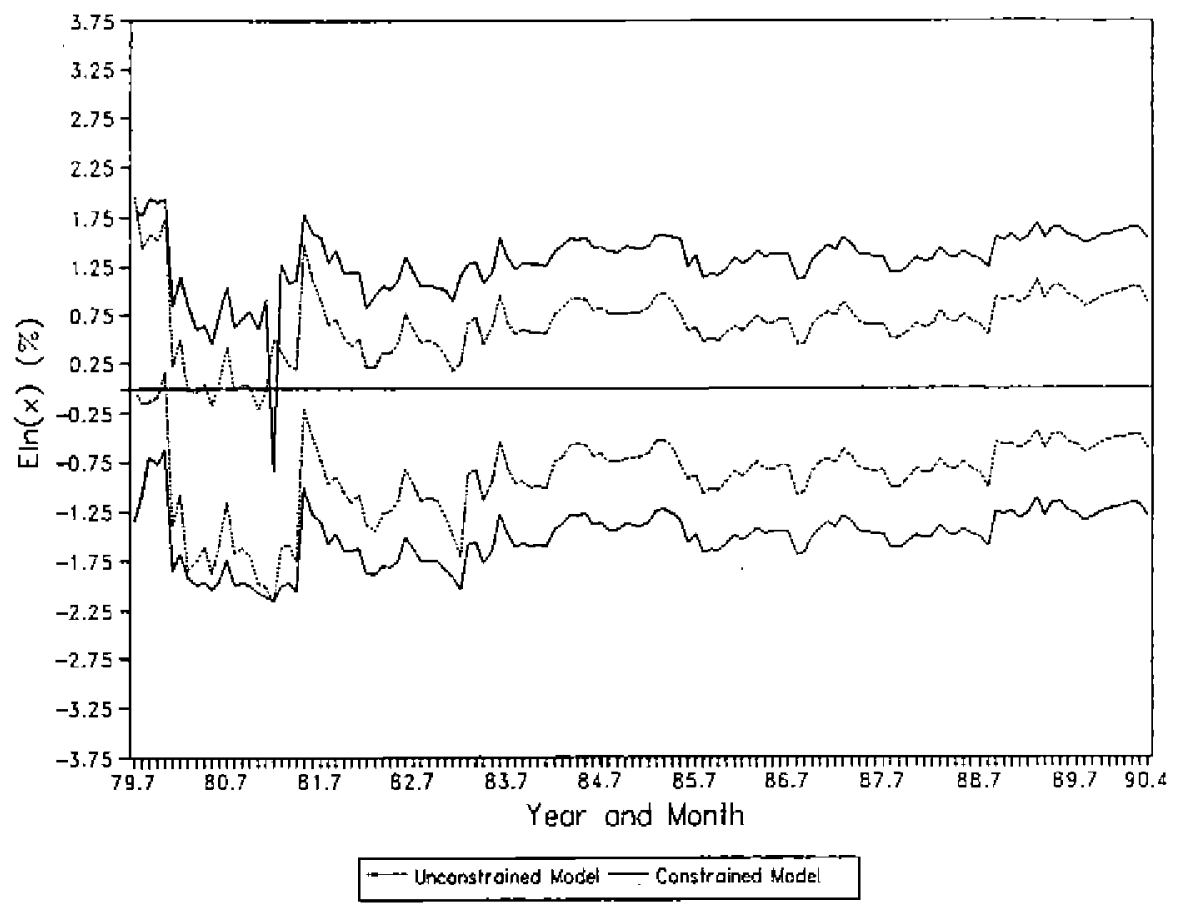


Figure $\bar{i}-95 \%$ confidence interval for the 3-montb expected devaluation: BP/US\$ under the Bretton Woods Regime

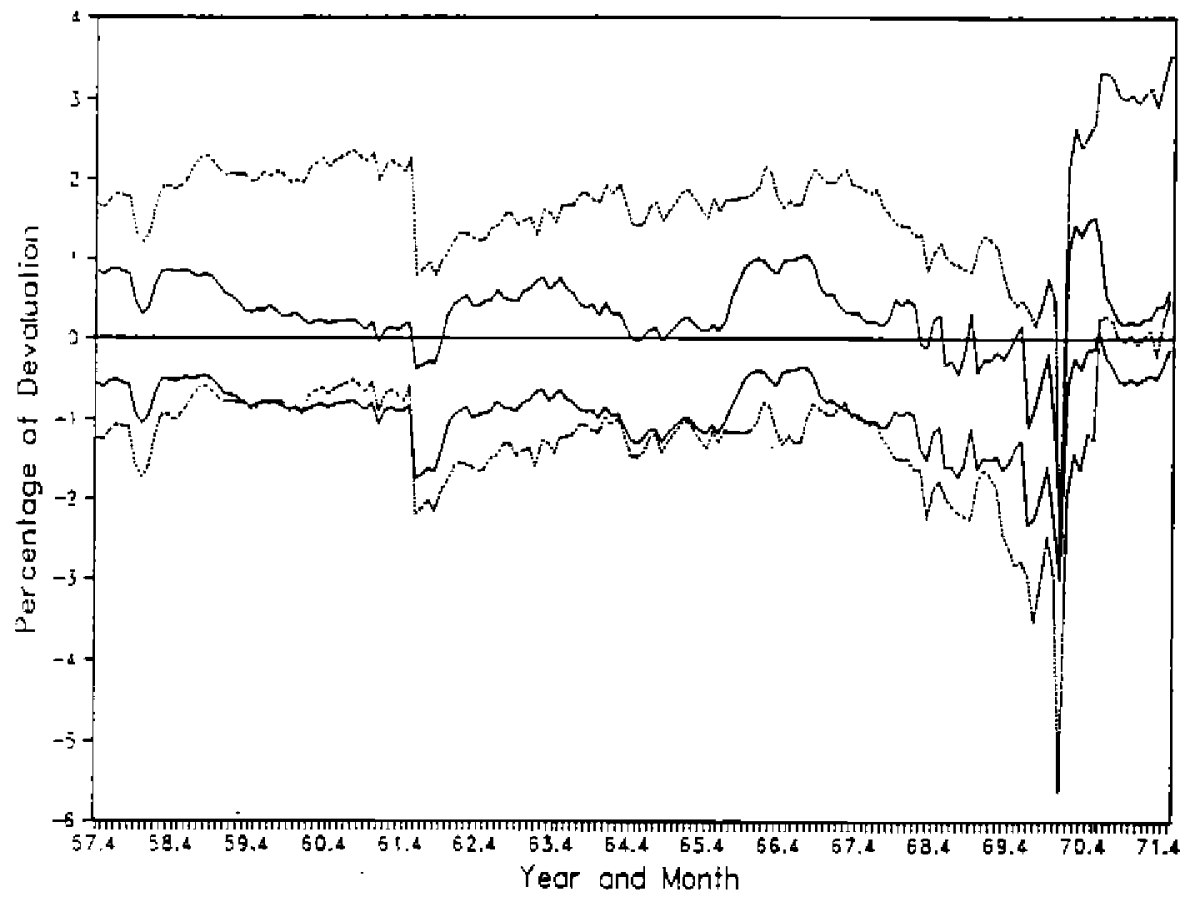


Figure 8-95\% conlidence interval for the 3- munt hexpected devaluation: DM/US\% under the Brethon Whods hegine

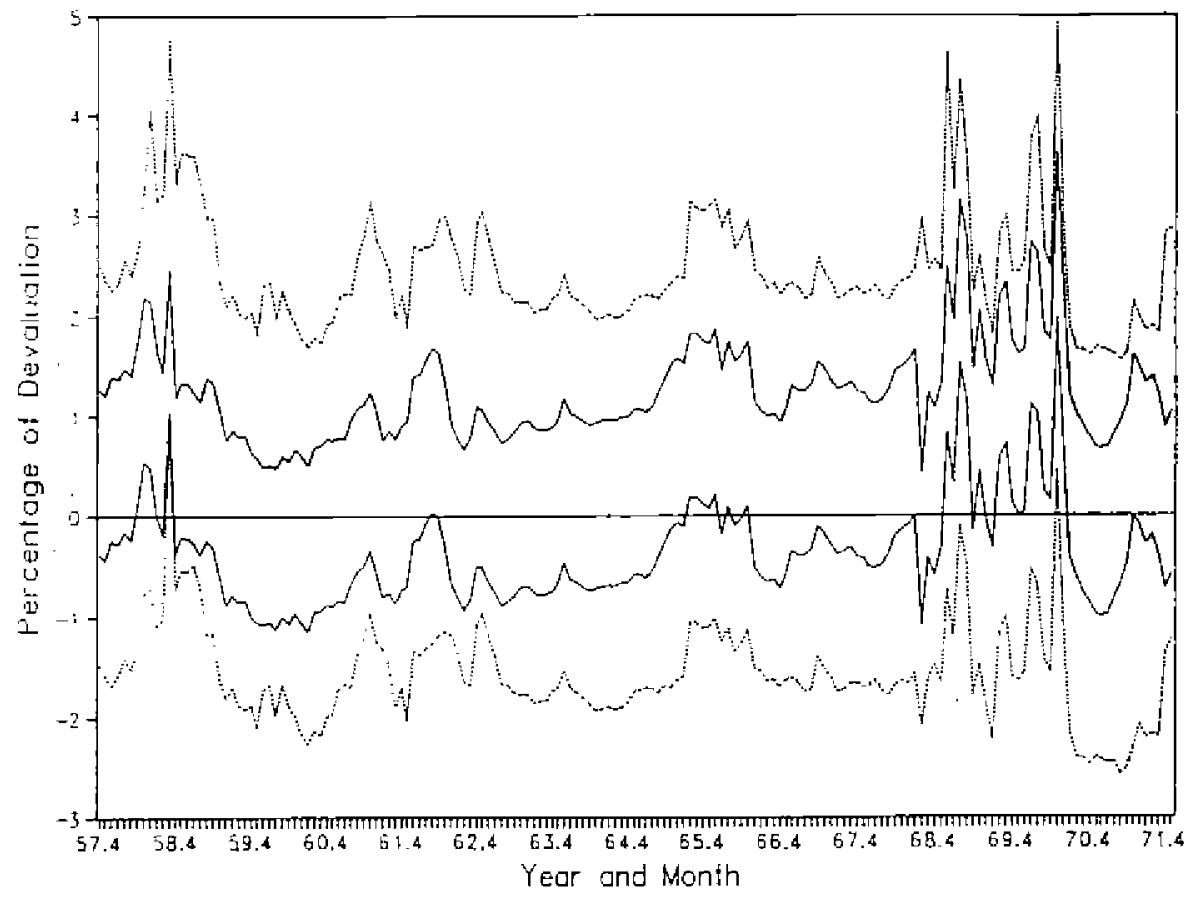


T"igure 9.-35\% contidence unterval for the 3-rnonth expected devaluation: BF/DM under the EMS

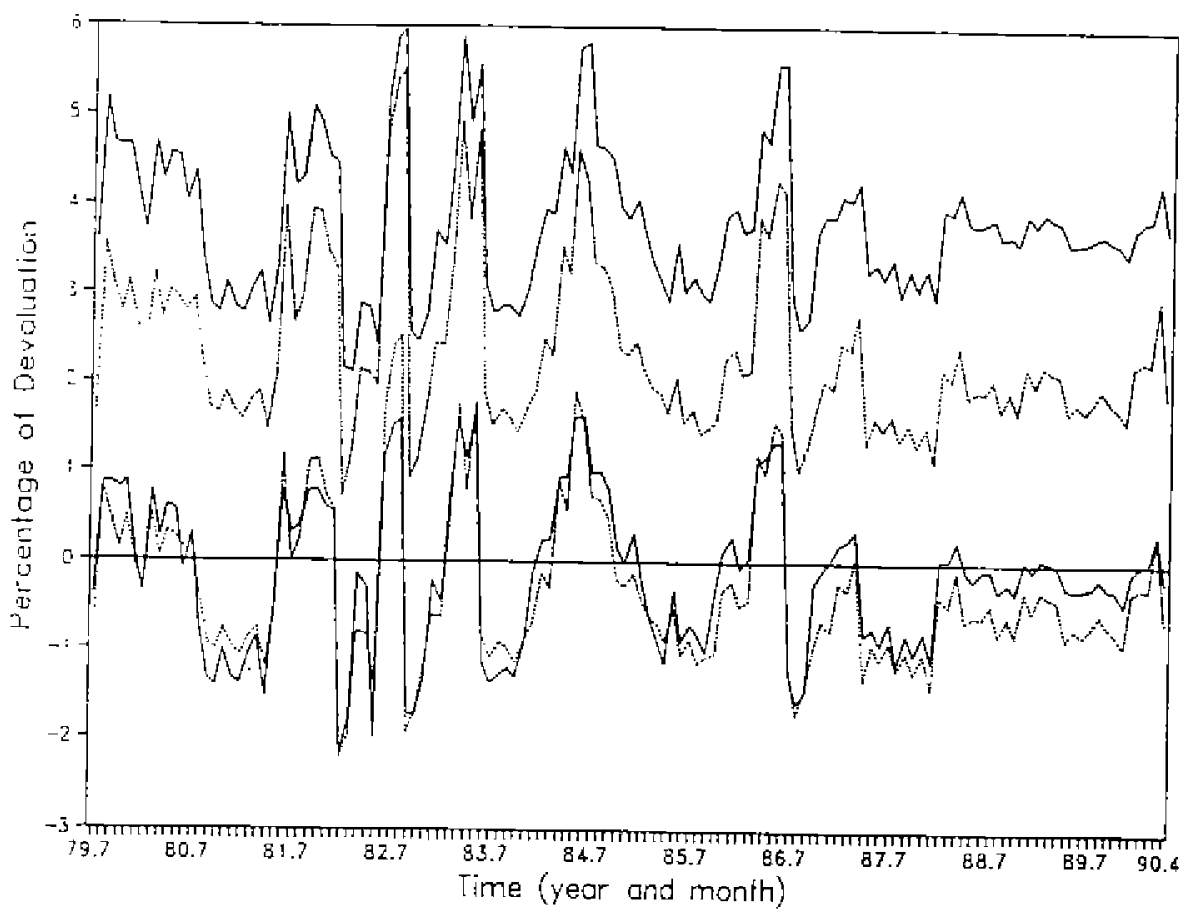




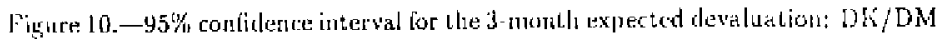
under the EMS

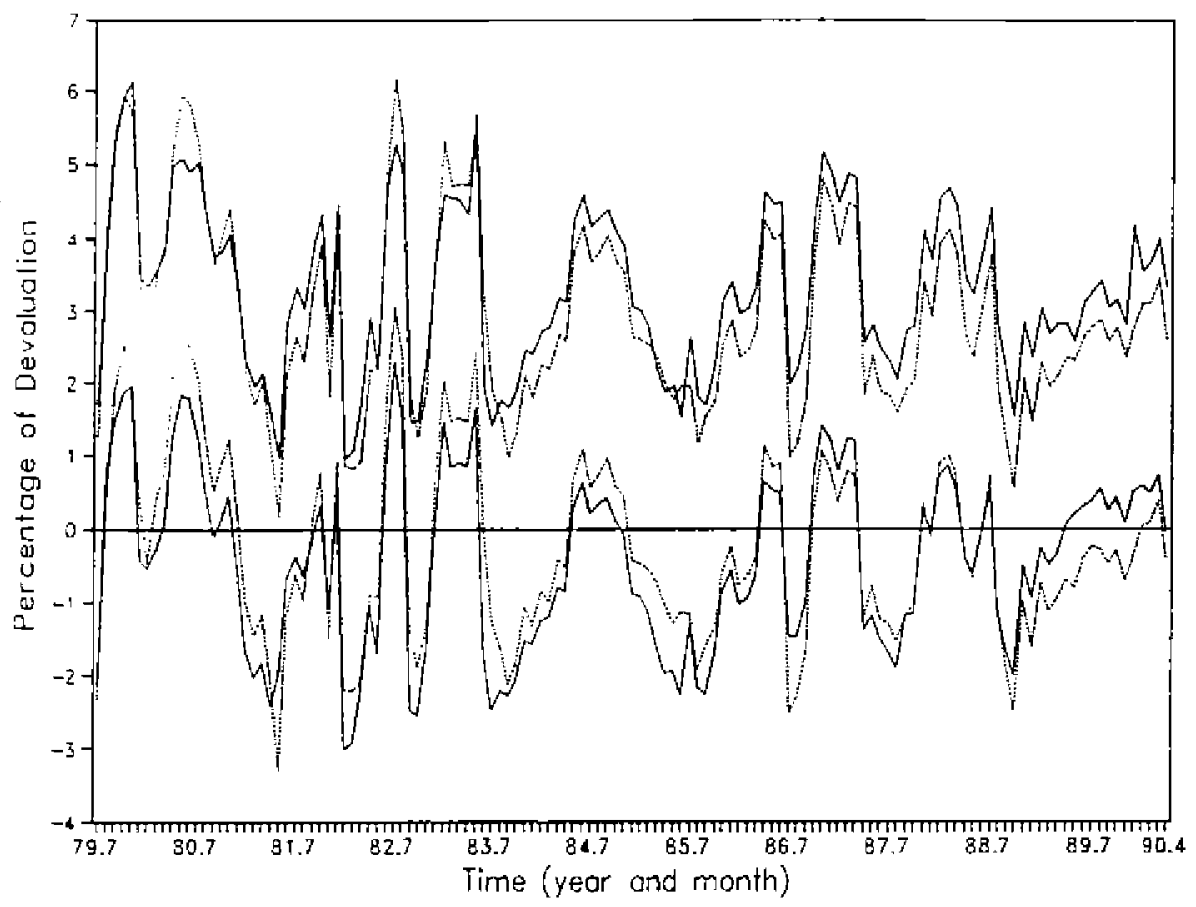


Figure $11 .-25 \%$ confidence interval for the 3-1]nith expected devaluation: FF/DM mider the EMS

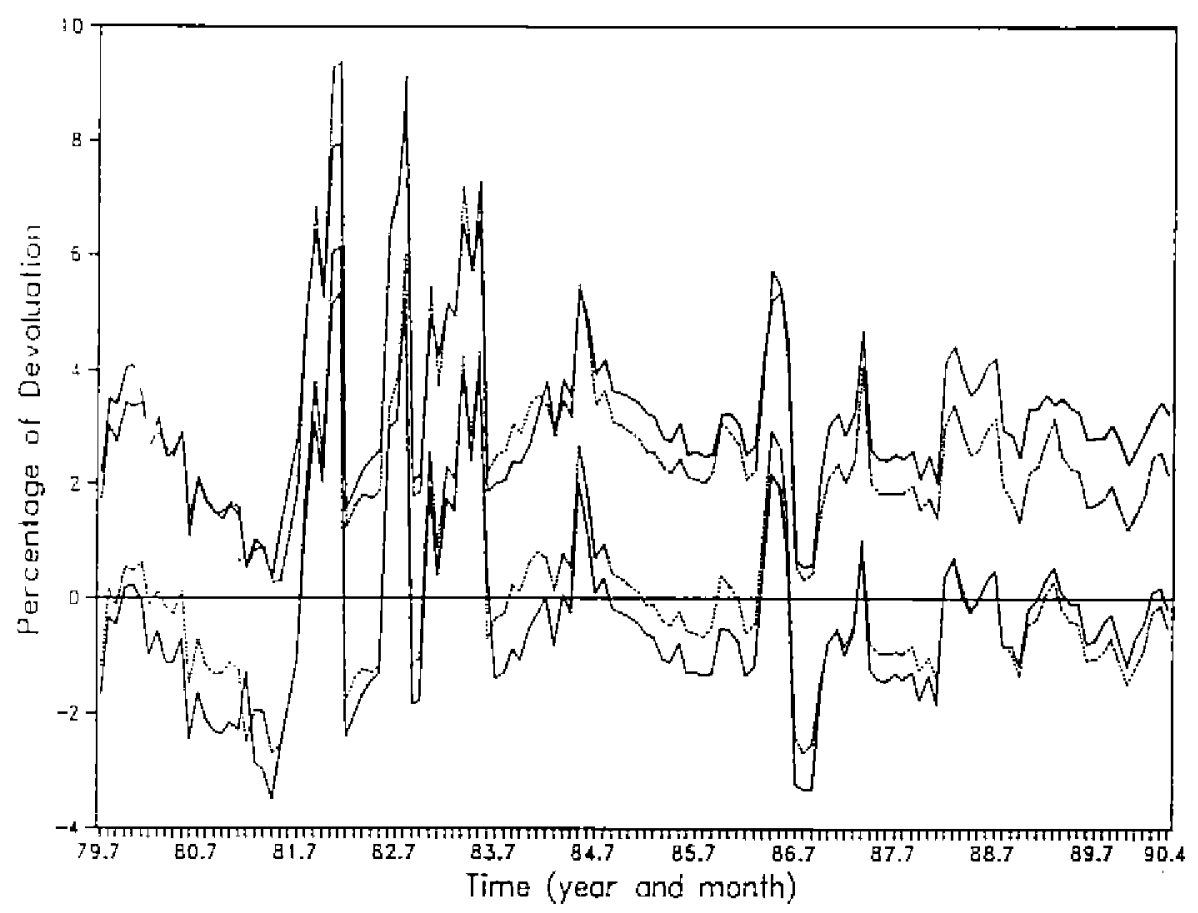


Figure 12,-95\% condidence interva! for the J-montle expectesi devitumitun: NG/DM under the EMS

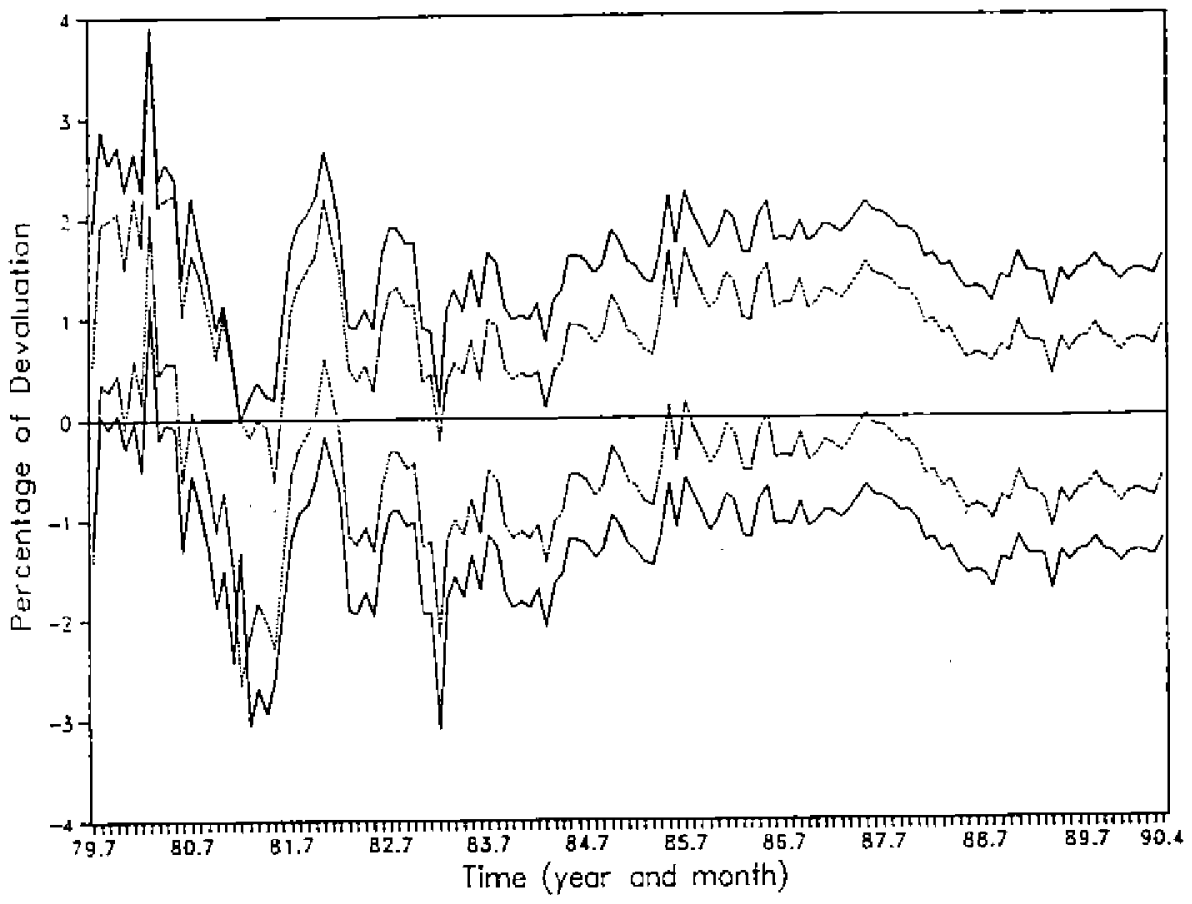


Figure 13.-Estumaled unconditional density curve for BP/US\$ under the Bretton Woods regine

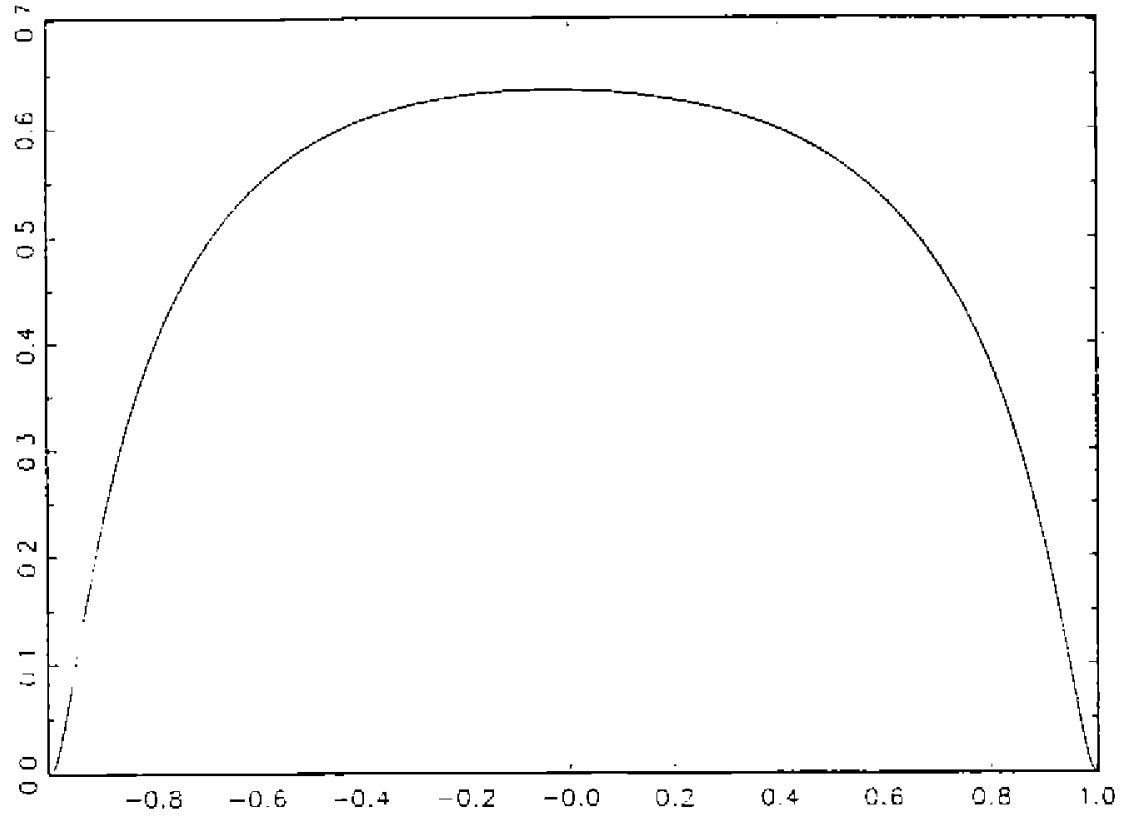


Figure 1 4.- - Estimated unconditional density curve for DM/US\$ under the Bretton Voods regime

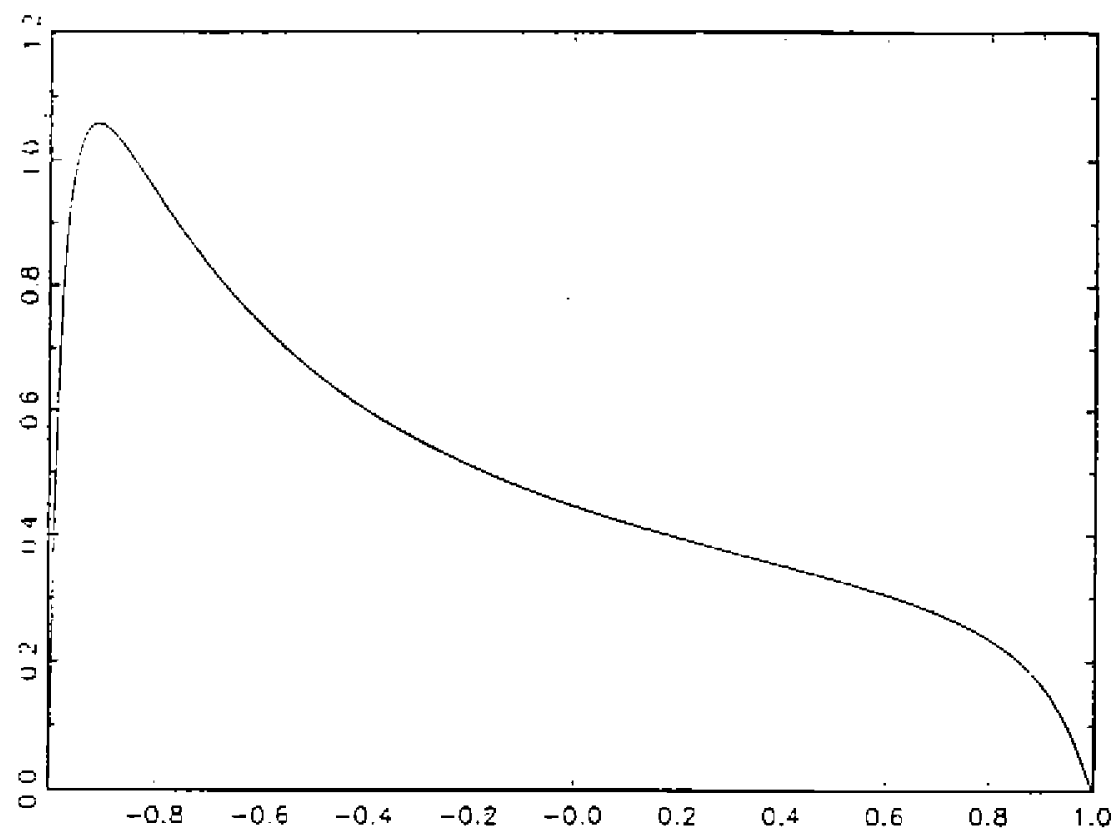


Figure 15.-Estimated unconditional density curve for BF/DM under the EMS

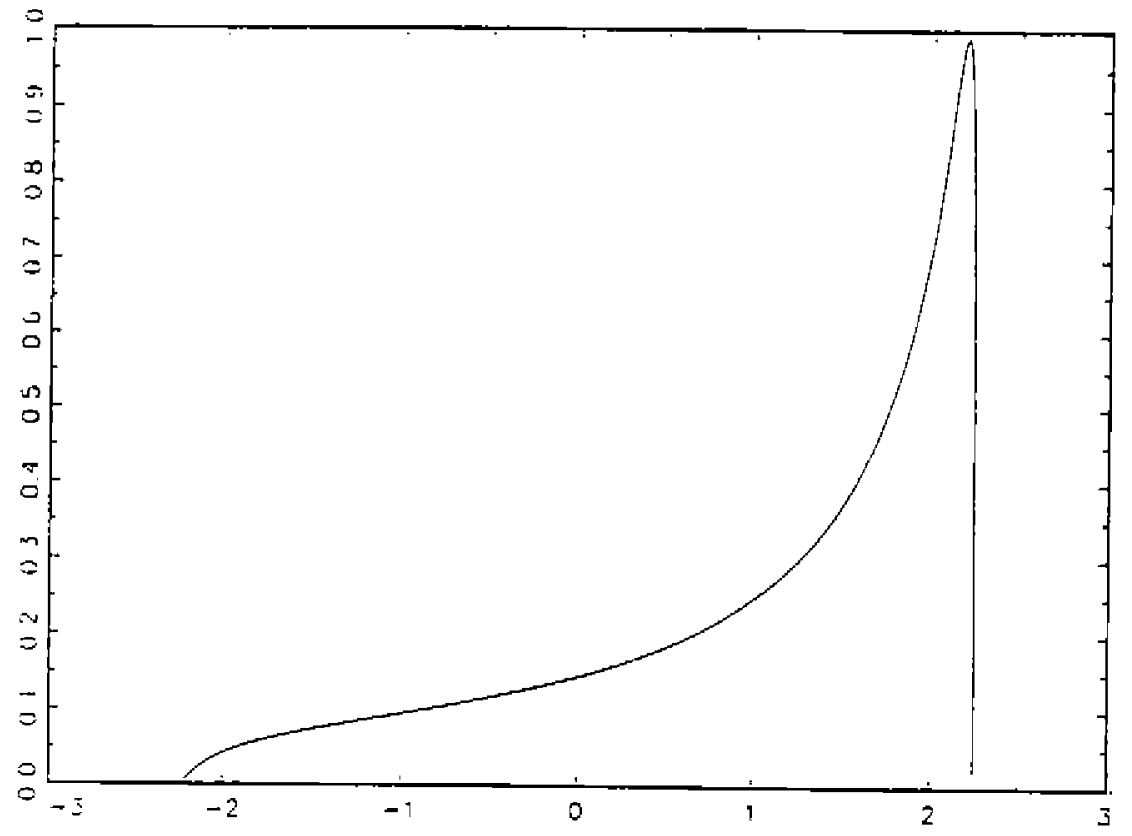


Figure 16.-Estimaled uncouditional density curve for DK/DM under the EMS

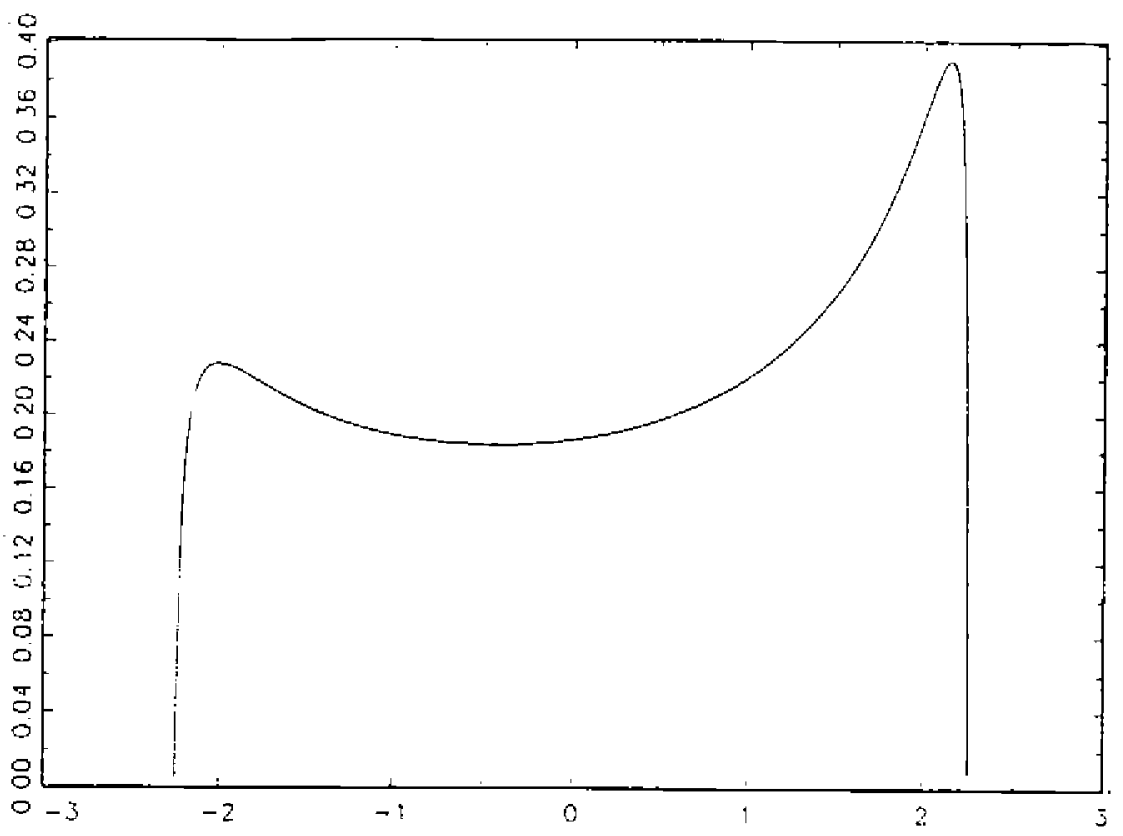


Figure [7.-Estimated unconditional density curve for FF/DM under the EMS

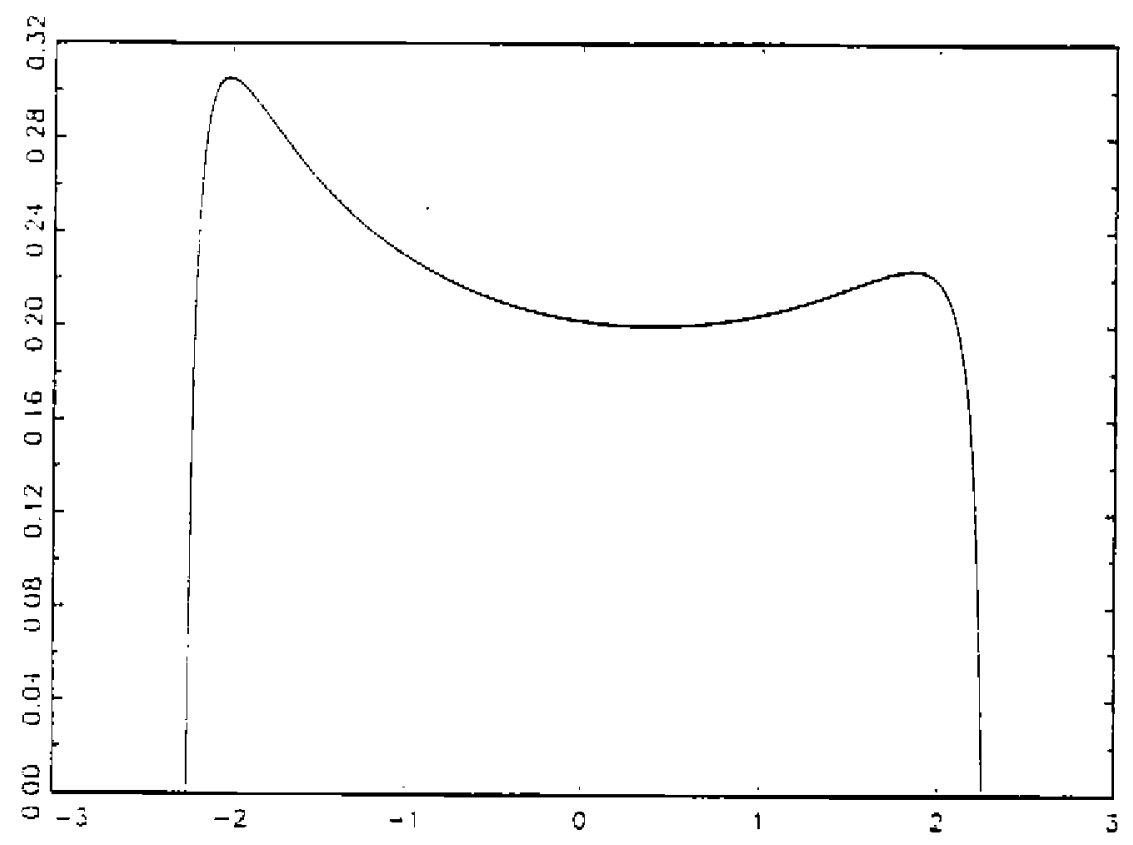


Figure 18.--Estimated unconditional density curve for NG/DM under the EMS

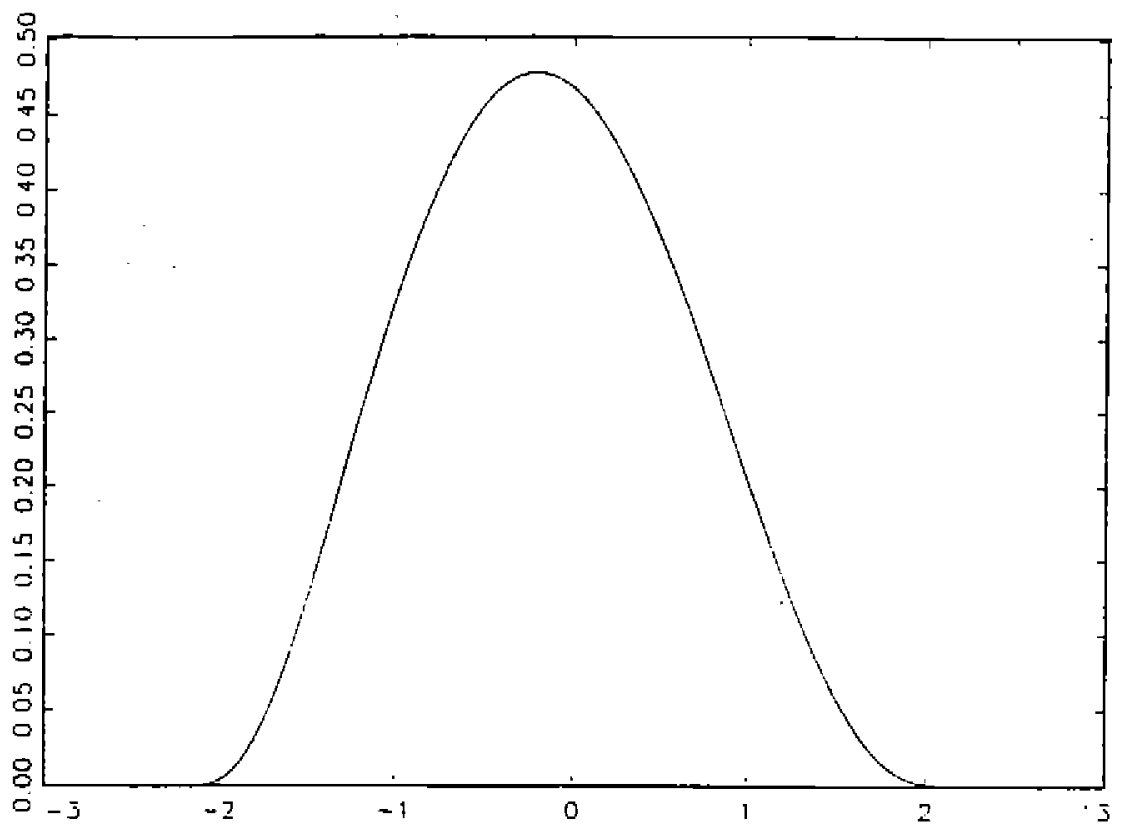

